\title{
Long-term treatment with haloperidol affects neuropeptide S and NPSR mRNA levels in the rat brain.
}

Running title: Haloperidol affects NPS/NPSR mRNA levels in the rat brain

\author{
Artur Palasz ${ }^{1}$, Ewa Rojczyk ${ }^{1}$, Milosz Golyszny ${ }^{2}$, Lukasz Filipczyk ${ }^{1}$, \\ John J. Worthington ${ }^{3}$, Ryszard Wiaderkiewicz ${ }^{1}$
}

\footnotetext{
${ }^{1}$ Department of Histology, School of Medicine in Katowice, Medical University of Silesia, Medyków Street 18, 40-752, Katowice, Poland

${ }^{2}$ Student Scientific Society, Medical University of Silesia, Poniatowskiego Street 15, 40-055

Katowice, Poland

${ }^{3}$ Manchester Immunology Group, University of Manchester, Oxford Road, Manchester M13 9PT, United Kingdom
}

Corresponding author : Artur Palasz PhD, Department of Histology, School of Medicine in Katowice, Medical University of Silesia, 18 Medykow Street, 40-752 Katowice, Poland e-mail: apalasz@sum.edu.pl tel: +48 322088363 


\begin{abstract}
The brainstem-derived neuropeptide S (NPS) has a multidirectional regulatory activity, especially as a potent anxiolytic factor. Accumulating data suggests that neuroleptics affect peptidergic signaling in various brain structures. However, there is no information regarding the influence of haloperidol on NPS and NPS receptor (NPSR) expression. We assessed NPS and NPSR mRNA levels in brains of rats treated with haloperidol using quantitative RealTime PCR. Chronic haloperidol treatment (4 weeks) led to a striking upregulation of NPS and NPSR expression in the rat brainstem. Conversely, the NPSR mRNA expression was decreased in the hippocampus and striatum. This stark increase of NPS in response to haloperidol treatment supports the hypothesis that this neuropeptide is involved in the dopamine-dependent anxiolytic actions of neuroleptics and possibly also in the pathophysiology of mental disorders. Furthermore, our findings underline the complex nature of potential interactions between dopamine receptors and brain peptidergic pathways, which has potential clinical applications.
\end{abstract}

Key words: neuropeptide S, NPSR, haloperidol, neuroleptics, brainstem

\title{
Significant outcomes
}

- For the first time, we assessed the influence of haloperidol on NPS/NPSR mRNA expression in the rat brain

- We proved a significant upregulation of NPS mRNA level in the rat brainstem after haloperidol administration

Limitations:

- We assessed only mRNA expression, protein level was not measured

- We did not determine receptor-ligand interactions nor downstream signaling pathways 
Introduction

Neuropeptide S (NPS) is a selective 20-amino acid ligand for the NPS receptor (NPSR), a Gs and Gq - coupled receptor formerly identified as orphan receptor GPR 154 (1). NPS is an endogenous modulator of a wide spectrum of physiological activities in the brain. It exerts anxiolytic effects, stabilizes arousal state, regulates food intake as well as plays a role in the pathomechanism of fear modulation and addiction (2-8). In the rat brain, expression of NPS is shown almost exclusively within the locus coeruleus, principal trigeminal nucleus and lateral parabrachial nucleus, whereas in mouse NPS expression in the Kölliker-Fuse nucleus has also been reported (9). In contrast to the specific expression of NPS, NPSR mRNA is abundant within the brain and has been detected in the olfactory bulb, piriform cortex, amygdala, hypothalamus, thalamus and brainstem (10). Receptor stimulation leads both to a release of $\mathrm{Ca}^{2+}$ reserves to the neuroplasm and to an increase of cAMP levels $(11,1)$. From a neuropsychiatric viewpoint, the most important role of NPS seems to be its activity at the level of neuronal pathways related to the neurobiology of fear (12). A number of behavioral tests prove that central or even intranasal NPS administration has a strong anxiolytic effect in rats, which may be related to an increase of dopamine release in the medial prefrontal cortex $(13,14)$. The stimulatory effect of NPS on dopaminergic signaling suggests that this neuropeptide might increase dopamine synthesis and/or its turnover within the synaptic cleft (14). Moreover, NPS application to organotypic hippocampal slices activated synaptic plasticity in CA1 and CA3 areas, whereas targeted NPS microinjection directly to the ventral CA1 was enough to reduce fear related behaviour in mice (15). Furthermore, under in vitro conditions NPS, acting through its receptor, weakens the neural activity stream from the dentate gyrus to the CA1 area (15). NPS peptide administration into the mouse amygdala results in conditioned fear elimination, but it has no effect before the conditioning process 
(16). Recent experiments on healthy individuals also suggest, that NPSR gene T-alleles could be connected with fear, excessive stress reaction and increased HPA axis stimulation (5). Moreover, NPSRl gene variation affects the glutamate/glutamine (Glx) levels in the rat cingulate cortex during induced panic attacks (17). Studies by Zhang et al. (18) prove that NPS expression in the locus coeruleus and a decrease of NPSR internalization level in the limbic system coexist with chronic pain and anxiety (24). On the other hand, NPS can stimulate inhibitory GABAergic transmission in the rat medial amygdala, reducing fear related responses (16). The NPS signaling may be also involved in the regulation of HPA axis acting as a part of negative feedback loop in the response to various stress stimuli (4). Another clinically intriguing report has associated NPSR polymorphisms with neuropsychiatric disorders including schizophrenia (19). Noteworthy, anxiety is considered as an important and relatively frequent symptom of schizophrenia, which is significantly connected with an elevated risk of severe consequences including suicidal behaviour (20). Post-traumatic stress disorder (PTSD) and obsessive compulsive disorder (OCD) are present in $38.3 \%$ of patients suffering from schizophrenia (21). Interestingly, some recent findings suggest a role of the NPS signaling in the regulation of motor functions at the level of basal ganglia $(22,23)$.

Haloperidol, a classical but still widely administered $\mathrm{D}_{2}$ receptor antagonist effectively reduces the psychosis suggesting impaired dopaminergic signaling as a key mechanism of positive schizophrenia symptoms (24). Noteworthy, haloperidol is a non-specific neuroleptic with affinity to numerous receptors, including dopamine D2, serotonin 5-HT2, $\alpha$-adrenergic and $\sigma$-opioid receptors (25-27). Haloperidol shows either potentially beneficial anxiolytic and sedative properties or a wide spectrum of unfavorable side effects including tardive dyskinesia, neuroleptic malignant syndrome, akathisia and QT-interval prolongation (28-30). Nevertheless, the neurochemical mechanism of anxiolytic and dyskinetic actions of 
neuroleptics, both classical and atypical, is so far poorly understood. Some reports show that atypical antipsychotics, but not haloperidol can upregulate the level of steroid $\mathrm{GABA}_{\mathrm{A}}$ receptor stimulators in the rat brain (31). In turn, the blockage of serotonin 5-HT2 receptors with haloperidol may be responsible for its anxiolytic effect (32). Hypothetically, the peptidergic signaling systems may play a significant role in the central regulation of anxietyrelated events.

Aims of the Study

Accumulating but still limited findings suggest that neuroleptics may affect peptidergic regulatory pathways in various brain structures. For example, both chlorpromazine and clozapine affect corticotropin-releasing hormone $(\mathrm{CRH})$ expression probably via activation of the PI3K/Akt signalling cascade, however PKC-related pathway may be also involved (33). Haloperidol stimulates CRH mRNA expression and also increases the gonadotropin-releasing hormone $(\mathrm{GnRH})$ secretion in the rat hypothalamus (34). In turn, both quetiapine and olanzapine are able to inhibit the release of $\mathrm{CRH}$ from isolated rat hypothalami and hippocampi (35). Haloperidol upregulates neurotensin levels in the rat striatum, hippocampus and the frontal cortex, but risperidone decreases the peptide expression (36). Conversely, long-term treatment with haloperidol decreases NPY mRNA levels in the rat amygdala and hippocampus, while olanzapine and clozapine show the same effect in the striatum, nucleus accumbens and anterior cingulated cortex (37). Long-term treatment with risperidone also downregulates the NPY mRNA expression in the rat hypothalamus (38). In contrast, a stimulatory effect of subchronically administered olanzapine on NPY expression is also 
suggested (39). Olanzapine increases calcitonin gene-related peptide (CGRP) immunoreactivity in the rat brain (40).

Despite these ongoing studies, almost no data exists regarding the interaction of neuroleptics with brain NPS signalling. We therefore examined the effect of administration of haloperidol, a classical butyrophenone type antipsychotic drug, on NPS and NPSR expression in the rat brain and showed a robust significant increase in brainstem NPS mRNA expression as a result of chronic drug administration.

Materials and methods

Animals

The experiments were performed on adult male Sprague-Dawley rats (2-3 months old, 180-210 g). We injected two groups of animals $(n=4)$ with either control vehicle (saline) or haloperidol ( $2 \mathrm{mg} / \mathrm{kg} / \mathrm{day})$ every day for 4 weeks ( 28 injections per rat). All procedures were conducted in a manner consistent with NIH Guidelines for Care and Use of Laboratory Animals and approved by the Local Bioethical Committee at the Medical University of Silesia (agreement no. 36/2012).

Material collection and reverse transcription

24 hours after the last drug administration, animals were anaesthetized with isoflurane. Then, the brains were quickly removed and we performed microsurgical excision of samples from hypothalamus, hippocampus, striatum and brainstem. After that, all samples were homogenized with an ultrasound homogenizer (Heildolph DIAX 900, Germany) in $1 \mathrm{ml}$ of 
TRIzol ${ }^{\circledR}$ Reagent (Life Technologies) and total mRNA was extracted and dissolved in $50 \mu 1$ of RNAse-free water. Transcription of mRNA into cDNA was performed by incubation in buffered solution of reverse transcriptase MMLV-RT with RNAsin, oligo-dT and a mix of nucleotides at $42{ }^{\circ} \mathrm{C}$ for 60 min using a DNA Thermal Cycler 480 (Perkin Elmer Inc., Waltham, MA). Initial mRNA solutions contained $5 \mu \mathrm{g}$ of RNA per $100 \mu \mathrm{l}$.

Quantitative real-time PCR

We performed quantitative Real-Time PCR reaction (qPCR) with the use of FastStart SYBR Green Master Mix (Roche) in a Light Cycler ® 96 (Roche) for 45 rounds. Expression levels of NPS and NPSR were compared with expression of housekeeping gene glyceraldehyde phosphate dehydrogenase (GAPDH). cDNA amplification was performed using the following primers: for NPS; Forward: 5' - TTGGAGTTATCCGGTCCTCTCTT 3', Reverse: 5'-TTGGAGTTATCCGGTCCTCTCTT-3', for NPSR; Forward: 5'TGCAAGGTGCAAAGATCCCA-3', Reverse: 5'-AATCTGCATCTCATGCCTCTC-3', for GAPDH: Forward: 5'-GTGAACGGATTTGGCCGTATCG-3', Reverse: 5'ATCACGCCACAGCTTTCCAGAGG-3'.

Statistics

Statistical analysis was done with Statistica (Systat Software). We presented data (on graphs) as mean \pm SEM. Mean differences between groups of animals were analyzed using non-parametric Kruskall-Wallis test. Differences were considered statistically significant at p $\leq 0,05$ 
Results

In the current study, rats treated chronically with haloperidol manifested strongly increased relative NPS mRNA expression in the brainstem; $128,75 \pm 6,48$ versus control: $1,08 \pm 0,33(\mathrm{p}=0,000246)$. Although, there is an unexpectedly massive (about 120 -fold) increase of NPS mRNA level in this region we excluded the effect of haloperidol on GAPDH expression, as mean $\mathrm{Cq}$ values for this gene are very similar for control animals $(15,65)$ and for haloperidol treated animals $(15,48)$. We have also found a trend for decreased NPS mRNA level in the hypothalamus: $13,79 \pm 0,36$ versus control: $15,59 \pm 4,09$, nevertheless this change was not statistically significant (Fig.1). The NPS mRNA expression in the hippocampus and striatum was undetected. After long-term administration of haloperidol NPSR mRNA expression was downregulated in the hippocampus; $5,6 \pm 4,03$ versus control: $15,76 \pm 3,86$ and striatum: $9,78 \pm 2,42$ versus control: $21,19 \pm 8,67$, unchanged in the hypothalamus 20,17 $\pm 0,81$ versus control: $24,01 \pm 2,65$ and highly increased in the brainstem: $60,36 \pm 10,48$ versus control: $24,86 \pm 4,59$ (Fig. 2).

\section{Discussion}

At present, there are relatively few reports concerning NPS expression changes related to antipsychotic drug activity. Studies on the influence of this group of pharmaceuticals on peptidergic regulatory pathways could be a source of hypothesis explaining alternative ways of their pharmacological effects. In our analysis we focused on the expression of the NPS and NPSR mRNA in selected brain structures of rats chronically treated with haloperidol. The 
results indicate that chronical drug administration may modulate the expression of NPS and NPSR mRNAs in selected rat brain regions.

The statistically significant elevation of the brainstem NPS mRNA level, after longterm haloperidol administration stays in agreement with our recent results showing that short and chronical treatment with the neuroleptics chlorpromazine and olanzapine increased the NPS mRNA expression in the rat hypothalamus (41). In addition, haloperidol stimulates the secretion of gonadotropin-releasing hormone (GnRH) (34) and increases corticotrophinreleasing hormone (CRF) mRNA expression in the rat hypothalamus (42). On the other hand, haloperidol, but not risperidone, elevates neurotensin levels in the rat striatum, hippocampus and frontal cortex. Conversely, in the occipital cortex, risperidone, but not haloperidol, reduces neurotensin expression (36). In contrast, long-term haloperidol administration decreases NPY mRNA expression in the rat amygdala and hippocampus while olanzapine and clozapine show the same effect in the nucleus accumbens, striatum and anterior cingulated cortex (18.). Similarly, chronically administered risperidone decreases the NPY mRNA level in the rat hypothalamus (38). Only olanzapine significantly decreases the NPY mRNA level in the lateral septal nucleus (37). A decrease in the hypothalamic NUCB2 and nesfatin-1 expression after chronical haloperidol administration was also recently reported (43). In our experiment, the NPS mRNA expression remains unchanged in hypothalamus after drug treatment. This result is in line with the study showing that hypothalamic NPY mRNA level did not change after long-term neuroleptic administration to rats (43).

Furthermore, it is suggested, that haloperidol can induce disturbances in the oxidativeantioxidative balance. It should be noted that the elevation of NPS expression observed in our study may be a part of neuronal protective mechanism against an extended treatment with this drug. Moreover, it was shown, that NPS can weaken lipid peroxidation processes in the 
mouse brain cortex, which confirms its neuroprotective activity during the occurrence of oxidative stress (44).

Single dose treatment with haloperidol and other typical antipsychotics may increase the number of spontaneously active dopaminergic cells in the rat brainstem (areas A9 and A10) whereas olanzapine and atypical neuroleptics stimulate cell populations in A10, but not A9 (45). The long-term treatment with neuroleptics proved that multiple haloperidol administration can lead to a decrease of the number of spontaneously active cells in A9 and A10 areas of the brainstem (46) whereas Stockton and Rasmussen (47) showed that chronic exposition to olanzapine results in a decreased number of active neurons in A10, but not in A9 area.

Interestingly, after long-term treatment with haloperidol, the NPSR mRNA levels were downregulated both in the hippocampus and striatum. This result is consistent with our recent finding that NPSR mRNA levels in the same structures were decreased after chronical chlorpromazine and olanzapine administration. Additionally, both short and long-term exposition to chlorpromazine decreased the NPS mRNA level in the hypothalamus (41). Presented phenomena are rather difficult to interpret without specific analysis of potential interactions between NPSR mode of action and dopaminergic signaling. Possibly, haloperidol may modulate the NPS-related synaptic plasticity in the hippocampus mediating any kinds of fear responses (15). Probably, the high elevation of NPS mRNA level in brainstem neurons may suggest an increased neuropeptide synthesis and release to the hippocampal formation and striatum. Thus, it should be taken into consideration that a decrease in NPSR mRNA expression could be a compensatory response to increased NPS concentration in these structures. In contrast, the NPSR mRNA level in brainstem was distinctly elevated after chronical haloperidol administration. Theoretically, this neuroleptic could increase the sensitivity and/or activity of NPS signaling in the brainstem and in consequence facilitate 
anxiolytic mechanisms. Importantly, the brainstem contains a distinct population of aminergic NPSR-expressing neurons (10) that play numerous central roles such as modulation of cortical glutamatergic transmission and maintaining the arousal state. We therefore can hypothesize that haloperidol may affect them indirectly via stimulation of NPS pathway. Chronic administration of haloperidol evokes several considerable side effects including prolonged sedation and tardive dyskinesia besides other motor disabilities.

Recent data suggested the role of NPS in locomotion and related these actions with dopaminergic signaling (44). It was shown that intracerebroventricular infusion of NPS to the striatum and substantia nigra increase the locomotor activity in rats. This effect is counteracted both by SHA 68 (a selective antagonist of NSPR) and antalarmin (a CRF-1 receptor blocker) suggesting that CRF plays a significant role in the NPS-related control of locomotion activity (23). Similarly, central injection of NPS abolished motor impairments evoked by dopaminergic neurotoxin 6-OHDA (22). Probably, NPS may stimulate dopamine release via selective activation of NPSR receptors in the extrapyramidal system (48). The observed downregulation of striatal NPSR mRNA expression suggests that pharmacological activity of haloperidol may also manifest at the level of NPS transmission in the basal ganglia, which may be one of the alternative ways of triggering dyskinetic side effects by this medication. Intriguingly, a recent study reports that haloperidol can also decrease the functional connectivity between substantia nigra and cortical motor regions, which may reflect motor disabilities (24).

Taken together, it is possible that dopamine may inhibit the expression of genes encoding some neuropeptides including NPS in certain brain regions. Thus, the blockage of dopamine receptors performed by haloperidol can result in compensational expression increase of the aforementioned proteins. Mechanisms of anxiolytic side effects of antipsychotics are not fully clarified, however it is suggested that the blockage of both 
dopamine $\mathrm{D}_{2}$ and serotonin 5- $\mathrm{HT}_{2}$ receptors may be responsible for the haloperidol anxiolytic action (32). Conversely, some reports show that atypical neuroleptics clozapine and olanzapine, but not haloperidol can increase the level of endogenous allopregnanolone and allotetrahydrodeoxycorticosterone (THDOC), two positive $\mathrm{GABA}_{\mathrm{A}}$ receptor modulators in the rat brain $(49,31,50)$.

In conclusion, the fact that haloperidol highly affected the level of NPS and NPSR mRNA expression in the rat brain supports the hypothesis that NPS plays a role in the anxiolytic actions of neuroleptics and possibly also in the pathophysiology of mental disorders; for example in the control of negative schizophrenia. It was also shown recently, that synthetic NPS is a potent anxiolytic agent, even in rodents with an innate predisposition to high anxiety. Thus, it is strongly suggested that NPS may be a promising, potentially beneficial medication in the treatment of anxiety disorders especially in patients with the high-risk variant (8). Our intriguing initial data requires further basic pharmacological and behavioural studies on the wide spectrum of antipsychotic drugs, but nonetheless highlights the complex nature of potential interactions between dopamine receptors and brain peptidergic pathways and opens up an array of future potential clinical applications.

\section{Authors Contributions}

Artur Palasz - article conception and design, drafting the manuscript, analysis and interpretation of data, Ewa Rojczyk, Milosz Golyszny, Lukasz Filipczyk -acquisition of data, analysis and interpretation of results, John J. Worthington -drafting the article and revising it

critically for important intellectual content, Ryszard Wiaderkiewicz - final review of the version to be published. 


\section{Financial Support}

This work was supported by the Medical University of Silesia grant for Department of Histology KNW-132/N/4/0.

\section{Statement of interest}

None

\section{Animal Welfare}

Experiments were conducted in a manner consistent with NIH Guidelines for Care and Use of Laboratory Animals.

\section{Ethical standards}

The authors assert that all procedures contributing to this work comply with the ethical standards of the relevant national and institutional guides on the care and use of laboratory animals

\section{References}




\section{PAPE HC, JUNGLING K, SEIDENBECHER T, LESTING J,REINSCHEID RK.}

Neuropeptide S: a transmitter system in the brain regulating fear and anxiety. Neuropharmacology 2010;58:29-34.

2. BECK B, FERNETTE B,STRICKER-KRONGRAD A. Peptide $S$ is a novel potent inhibitor of voluntary and fast-induced food intake in rats. Biochem Biophys Res Commun 2005;332:859-865.

3. CANNELLA N, KALLUPI M, RUGGERI B, CICCOCIOPPO R,UBALDI M. The role of the neuropeptide $\mathrm{S}$ system in addiction: focus on its interaction with the CRF and hypocretin/orexin neurotransmission. Prog Neurobiol 2013;100:48-59.

\section{CHAUVEAU F, LANGE MD, JUNGLING K, LESTING J, SEIDENBECHER T,PAPE} HC. Prevention of stress-impaired fear extinction through neuropeptide s action in the lateral amygdala. Neuropsychopharmacology 2012;37:1588-1599.

5. KUMSTA R, CHEN FS, PAPE HC,HEINRICHS M. Neuropeptide S receptor gene is associated with cortisol responses to social stress in humans. Biol Psychol 2013;93:304-307. 6. OISHI M, KUSHIKATA T, NIWA Het al. Endogenous neuropeptide S tone influences sleep-wake rhythm in rats. Neurosci Lett 2014;581:94-97.

7. PULGA A, RUZZA C, RIZZI A, GUERRINI R,CALO G. Anxiolytic- and panicolytic-like effects of Neuropeptide S in the mouse elevated T-maze. Eur J Neurosci 2012;36:3531-3537. 8. SLATTERY DA, NAIK RR, GRUND Tet al. Selective breeding for high anxiety introduces a synonymous SNP that increases neuropeptide S receptor activity. J Neurosci 2015;35:4599-4613.

9. CLARK SD, DUANGDAO DM, SCHULZ Set al. Anatomical characterization of the neuropeptide $\mathrm{S}$ system in the mouse brain by in situ hybridization and immunohistochemistry. J Comp Neurol 2011;519:1867-1893. 
10. XU YL, GALL CM, JACKSON VR, CIVELLI O,REINSCHEID RK. Distribution of neuropeptide $\mathrm{S}$ receptor mRNA and neurochemical characteristics of neuropeptide $\mathrm{S}$ expressing neurons in the rat brain. J Comp Neurol 2007;500:84-102.

11. GUERRINI R, SALVADORI S, RIZZI A, REGOLI D,CALO G. Neurobiology, pharmacology, and medicinal chemistry of neuropeptide S and its receptor. Med Res Rev 2010;30:751-777.

12. WEGENER G, FINGER BC, ELFVING Bet al. Neuropeptide $S$ alters anxiety, but not depression-like behaviour in Flinders Sensitive Line rats: a genetic animal model of depression. Int J Neuropsychopharmacol 2012;15:375-387.

13. LUKAS M,NEUMANN ID. Nasal application of neuropeptide $S$ reduces anxiety and prolongs memory in rats: social versus non-social effects. Neuropharmacology 2012;62:398405.

14. SI W, ALUISIO L, OKAMURA Net al. Neuropeptide S stimulates dopaminergic neurotransmission in the medial prefrontal cortex. J Neurochem 2010;115:475-482. 15. DINE J, IONESCU IA, STEPAN Jet al. Identification of a role for the ventral hippocampus in neuropeptide S-elicited anxiolysis. PLoS One 2013;8:e60219. 16. JUNGLING K, SEIDENBECHER T, SOSULINA Let al. Neuropeptide S-mediated control of fear expression and extinction: role of intercalated GABAergic neurons in the amygdala. Neuron 2008;59:298-310.

17. RULAND T, DOMSCHKE K, SCHUTTE Vet al. Neuropeptide S receptor gene variation modulates anterior cingulate cortex Glx levels during CCK-4 induced panic. Eur Neuropsychopharmacol 2015.

18. ZHANG S, JIN X, YOU Zet al. Persistent nociception induces anxiety-like behavior in rodents: role of endogenous neuropeptide S. Pain 2014;155:1504-1515. 
19. LENNERTZ L, QUEDNOW BB, SCHUHMACHER Aet al. The functional coding variant Asn107Ile of the neuropeptide S receptor gene (NPSR1) is associated with schizophrenia and modulates verbal memory and the acoustic startle response. Int $\mathbf{J}$ Neuropsychopharmacol 2012;15:1205-1215.

20. GARAY RP, SAMALIN L, HAMEG A,LLORCA PM. Investigational drugs for anxiety in patients with schizophrenia. Expert Opin Investig Drugs 2015;24:507-517.

21. BRAGA RJ, REYNOLDS GP,SIRIS SG. Anxiety comorbidity in schizophrenia. Psychiatry Res 2013;210:1-7.

22. DIDONET JJ, CAVALCANTE JC, SOUZA LDE Set al. Neuropeptide S counteracts 6OHDA-induced motor deficits in mice. Behav Brain Res 2014;266:29-36.

23. LI MS, PENG YL, JIANG JHet al. Neuropeptide S Increases locomotion activity through corticotropin-releasing factor receptor 1 in substantia nigra of mice. Peptides 2015;71:196201.

24. GASS N, SCHWARZ AJ, SARTORIUS Aet al. Haloperidol modulates midbrainprefrontal functional connectivity in the rat brain. Eur Neuropsychopharmacol 2013;23:13101319.

25. COBOS EJ, DEL POZO E,BAEYENS JM. Irreversible blockade of sigma-1 receptors by haloperidol and its metabolites in guinea pig brain and SH-SY5Y human neuroblastoma cells. J Neurochem 2007;102:812-825.

26. ROTH BL, MELTZER HY,KHAN N. Binding of typical and atypical antipsychotic drugs to multiple neurotransmitter receptors. Adv Pharmacol 1998;42:482-485.

27. SEEMAN P,TALLERICO T. Antipsychotic drugs which elicit little or no parkinsonism bind more loosely than dopamine to brain D2 receptors, yet occupy high levels of these receptors. Mol Psychiatry 1998;3:123-134. 
28. BUDDEN MG. A comparative study of haloperidol and diazepam in the treatment of anxiety. Curr Med Res Opin 1979;5:759-765.

29. LEUCHT S, CIPRIANI A, SPINELI Let al. Comparative efficacy and tolerability of 15 antipsychotic drugs in schizophrenia: a multiple-treatments meta-analysis. Lancet 2013;382:951-962.

30. STRACINA T, SLANINOVA I, POLANSKA Het al. Long-Term Haloperidol Treatment Prolongs QT Interval and Increases Expression of Sigma 1 and IP3 Receptors in Guinea Pig Hearts. Tohoku J Exp Med 2015;236:199-207.

31. MARX CE, SHAMPINE LJ, DUNCAN GEet al. Clozapine markedly elevates pregnenolone in rat hippocampus, cerebral cortex, and serum: candidate mechanism for superior efficacy? Pharmacol Biochem Behav 2006;84:598-608.

32. MILLAN MJ, BROCCO M, GOBERT A, SCHREIBER R,DEKEYNE A. S-16924 [(R)2-[1-[2-(2,3-dihydro-benzo[1,4]dioxin-5-yloxy)-ethyl]- pyrrolidin-3yl]-1-(4-fluorophenyl)ethanone], a novel, potential antipsychotic with marked serotonin1A agonist properties: III. Anxiolytic actions in comparison with clozapine and haloperidol. J Pharmacol Exp Ther 1999;288:1002-1014.

33. BASTA-KAIM A, BUDZISZEWSKA B, JAWORSKA-FEIL Let al. Antipsychotic drugs inhibit the human corticotropin-releasing-hormone gene promoter activity in neuro-2A cellsan involvement of protein kinases. Neuropsychopharmacology 2006;31:853-865.

34. UMATHE SN, WANJARI MM, MANNA SS,JAIN NS. A possible participation of gonadotropin-releasing hormone in the neuroleptic and cataleptic effect of haloperidol. Neuropeptides 2009;43:251-257.

35. TRINGALI G, LISI L, DE SIMONE MLet al. Effects of olanzapine and quetiapine on corticotropin-releasing hormone release in the rat brain. Prog Neuropsychopharmacol Biol Psychiatry 2009;33:1017-1021. 
36. GRUBER SH, NOMIKOS GG,MATHE AA. Effects of haloperidol and risperidone on neurotensin levels in brain regions and neurotensin efflux in the ventral striatum of the rat. Neuropsychopharmacology 2002;26:595-604.

37. HUANG XF, DENG C,ZAVITSANOU K. Neuropeptide Y mRNA expression levels following chronic olanzapine, clozapine and haloperidol administration in rats. Neuropeptides 2006;40:213-219.

38. KURSUNGOZ C, AK M,YANIK T. Effects of risperidone treatment on the expression of hypothalamic neuropeptide in appetite regulation in Wistar rats. Brain Res 2015;1596:146155.

39. FERNO J, VARELA L, SKREDE Set al. Olanzapine-induced hyperphagia and weight gain associate with orexigenic hypothalamic neuropeptide signaling without concomitant AMPK phosphorylation. PLoS One 2011;6:e20571.

40. ANGELUCCI F, GRUBER SH, CALTAGIRONE C,MATHE AA. Differential effects of olanzapine, haloperidol and risperidone on calcitonin gene-related peptide in the rat brain. Neuropeptides 2008;42:535-541.

41. PALASZ A, ROJCZYK E. Neuroleptics affect neuropeptide S and NPSR mRNA levels in the rat brain. J Mol Neurosci 2015 [epublished ahead of print]

42. PARK SW, CHOI SM, LEE JGet al. Differential effects of ziprasidone and haloperidol on immobilization-stress-induced CRF mRNA expression in the hypothalamic paraventricular nucleus of rats. Neuropsychobiology 2011;63:29-34.

43. ROJCZYK E, PALASZ A,WIADERKIEWICZ R. Effect of short and long-term treatment with antipsychotics on orexigenic/anorexigenic neuropeptides expression in the rat hypothalamus. Neuropeptides 2015;51:31-42. 
44. CASTRO AA, MORETTI M, CASAGRANDE TSet al. Neuropeptide S produces hyperlocomotion and prevents oxidative stress damage in the mouse brain: a comparative study with amphetamine and diazepam. Pharmacol Biochem Behav 2009;91:636-642. 45. RASMUSSEN K, HSU MA, YANG Y. The orexin-1 receptor antagonist SB-334867 blocks the effects of antipsychotics on the activity of A9 and A10 dopamine neurons: implications for antipsychotic therapy. Neuropsychopharmacology 2007;32:786-792. 46. WHITE FJ,WANG RY. Differential effects of classical and atypical antipsychotic drugs on A9 and A10 dopamine neurons. Science 1983;221:1054-1057.

47. STOCKTON ME,RASMUSSEN K. Electrophysiological effects of olanzapine, a novel atypical antipsychotic, on A9 and A10 dopamine neurons. Neuropsychopharmacology 1996;14:97-105.

48. MOCHIZUKI T, KIM J,SASAKI K. Microinjection of neuropeptide S into the rat ventral tegmental area induces hyperactivity and increases extracellular levels of dopamine metabolites in the nucleus accumbens shell. Peptides 2010;31:926-931.

49. BARBACCIA ML, AFFRICANO D, PURDY RH, MACIOCCO E, SPIGA F,BIGGIO G. Clozapine, but not haloperidol, increases brain concentrations of neuroactive steroids in the rat. Neuropsychopharmacology 2001;25:489-497.

50. MEAD A, LI M,KAPUR S. Clozapine and olanzapine exhibit an intrinsic anxiolytic property in two conditioned fear paradigms: contrast with haloperidol and chlordiazepoxide. Pharmacol Biochem Behav 2008;90:551-562. 


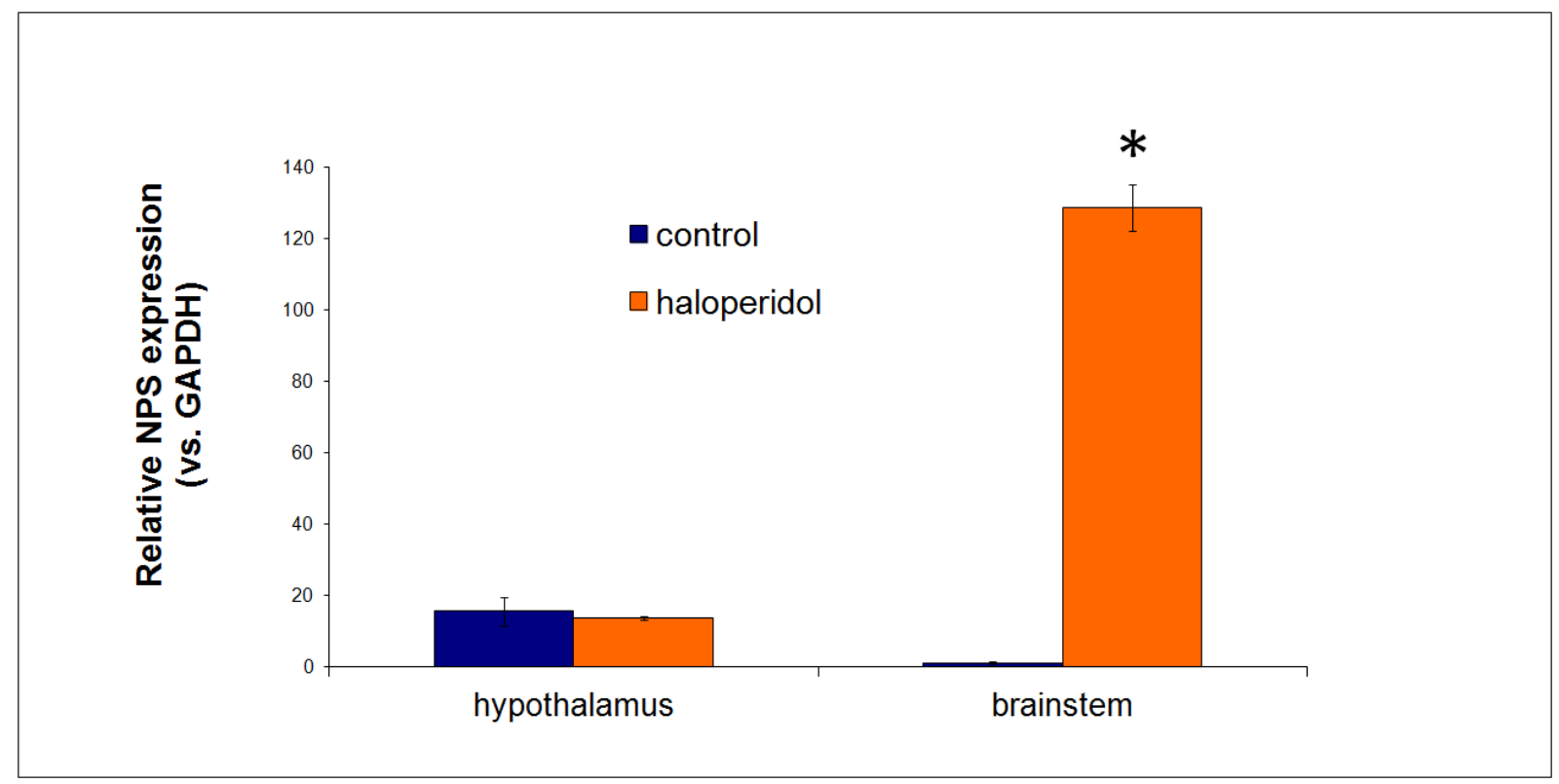

Fig. 1. Quantitative PCR results of relative neuropeptide $S$ mRNA expression levels in the rat hypothalamus and brainstem $(n=4)$. Data are presented as mean \pm SEM. Statistical analysis was performed using non-parametric Kruskal-Wallis test. Differences were considered significant at $\mathrm{p} \leq$ 0,05 (asterisk). 


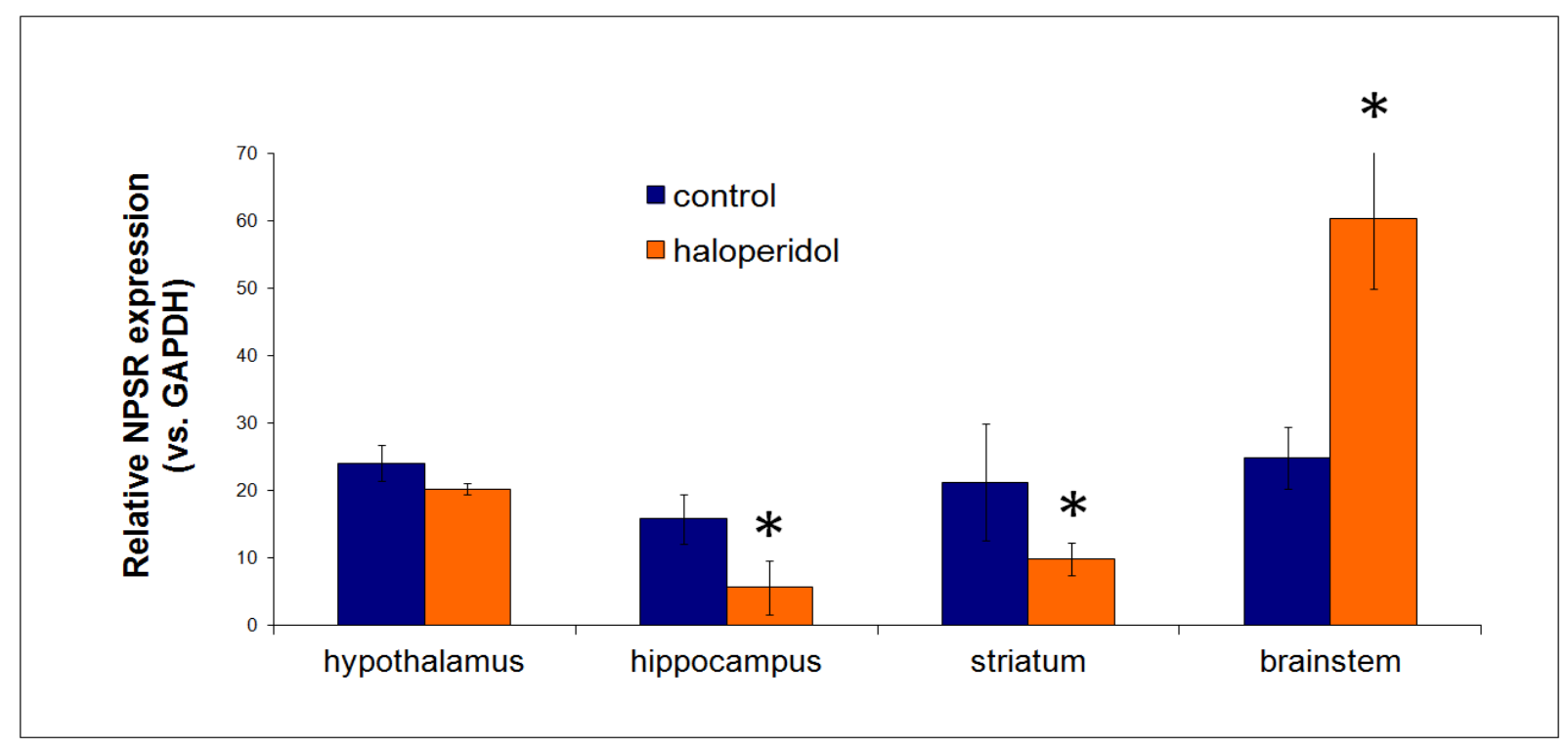

Fig. 2. Quantitative PCR results of relative NPSR mRNA expression levels in the selected rat brain regions $(n=4)$. Data are presented as mean \pm SEM. Statistical analysis was performed using nonparametric Kruskal-Wallis test. Differences were considered significant at $p \leq 0,05$. (asterisks). 